analecta polit. | Vol. 10 | No. 19 | PP. 30-55

| julio-diciembre | 2020 | ISSN-e: 2390-0067 (en línea) | Medellín-Colombia

doi: http://dx.doi.org/10.18566/apolit.v10n19.a02

\title{
Focus o estilo: \\ ¿qué intereses defienden y cómo se comportan los concejales de la ciudad de Barranquilla?
}

Cómo citar

este artículo en APA:

Guzmán Mendoza, C. E.

y Rojano, C. A. (2020).

Focus o estilo: ¿qué

intereses defienden y

cómo se comportan

los concejales de la

ciudad de Barranquilla,

en Colombia? Analecta

Política, 10(19), 30-55.

Fecha de recepción:

01.04.2020

Fecha de aceptación:

07.05.2020
CARLOS ENRIQUE GUZMÁN MENDOZA

Doctor en Ciencia Política

Universidad del Atlántico, Colombia

ceguzman@mail.uniatlantico.edu.co

\section{CARLOS ALBERTO ROJANO LLINAS}

Magister en Ciencia Política y Gobierno

Universidad del Norte, Colombia carlosrojanoll1215@gmail.com 


\section{Resumen}

Este artículo aproximó el análisis del rol de la representación política de los concejales de la ciudad de Barranquilla, en Colombia, a partir de la doble dimensión: focus (qué intereses representan) y estilo (si se comportan siguiendo instrucciones o, por el contrario, siguiendo sus propios intereses). Asimismo, estudió el conocimiento sobre las características sociopolíticas y demográficas de la élite política local de la ciudad y la identificación y la definición de los factores que influyen (explican) la configuración del papel de estos frente a la representación política. Del mismo modo, a partir de las actitudes, creencias y percepciones de los concejales, se busca responder a interrogantes relacionados con la democracia, sus actores e instituciones, las pautas políticas y las reglas de juego político local. Finaliza el artículo, resaltando, en el caso colombiano, la escasa literatura sobre élites políticas locales y, por tanto, la necesidad de ahondar en el estudio y conocimiento de los representantes más cercanos a los ciudadanos.

Palabras clave: democracia, representación política, élite política, focus, estilo, representación política.

\section{Abstract}

This article approached the analysis of the role of the political representation of the councilors of the city of Barranquilla, in Colombia, from the double dimension: focus (what interests they represent) and style (if they behave following instructions or, on the contrary, following their own interests). Likewise, it studied the knowledge on the socio-political and demographic characteristics of the local political elite of the city as well as the identification and definition of the factors that influence (or explain) the configuration of their role vis-à-vis their political representation. Similarly, based on the attitudes, beliefs and perceptions of the councilors, it also seeks to answer questions related to democracy, its actors and institutions, political guidelines and the rules of the local political game. The article ends highlighting the scarce literature on local political elites in the Colombian case and, therefore, the need to delve into the study and knowledge of the citizens' closest representatives.

Keywords: democracy, political representation, political elite, focus, style, political representation. 
Quien hace política aspira al poder; al poder como medio para la consecución de otros fines (idealistas o egoístas) o al poder "por el poder", para gozar del sentimiento de prestigio que él confiere. Max Weber

\section{Introducción}

La sensación de lejanía entre los ciudadanos y los políticos es un lugar común cuando se habla de los problemas actuales de la democracia (Subirats, 2012, p. 29) representativa. Tal apreciación resulta común e, incluso, cotidiana cuando la distancia entre unos y otros se hace evidente en el momento de evaluar el papel que desempeñan quienes dicen representar y las funciones que institucionalmente se asignan a los espacios de representación. O, como lo afirman Marenghi y García (2006, p. 29), "en las democracias representativas, los asuntos acerca de la relación entre representantes y representados despierta no pocas controversias cuando no conflictos de difícil resolución”.

La pérdida de apoyo y la insatisfacción con el rendimiento de las instituciones democráticas en América Latina se convirtieron en una silenciosa enfermedad que se hizo evidente a largo de la región durante 2019. ${ }^{1}$ La insatisfacción dio paso a la protesta; y está a la violencia. Ardió América Latina. La gente se tomó las calles de las principales ciudades en Brasil, Chile, Ecuador, Bolivia, Colombia, cuando no de México o de Haití. El denominador común de la protesta social podríamos encontrarlo en una sociedad desencantada y desconfiada, conformada por una amplia franja de clase media empoderada, de jóvenes con conciencia política y social que, aupados por los ejemplos de los movimientos y protestas sociales de París, Barcelona o Hong Kong, por ejemplo, se hartaron de la élite política y económica tradicional. Sin temor a equivocarnos, se puede afirmar que desde el inicio de la transición a la democracia la región pocas veces experimentó un periodo tan convulsionado como el que aún no se termina de vivir. ${ }^{2}$

1 La democracia en América Latina está en problemas. El mensaje que nos transmite la encuesta de opinión realizada por Latinobarómetro en 2018 es un mensaje de insatisfacción con el funcionamiento de esta y de sus instituciones. Desde 2009 hasta hoy, la insatisfacción ha aumentado significativamente al pasar del 51 al 71\%. Esto podría entenderse, simplemente, como que a los latinoamericanos no nos gusta la forma democrática que hoy vive la región. Que algo sucede con los vínculos, no solo procedimentales sino sustantivos, entre representantes y representados, entre gobernantes y gobernados.

2 En el momento de escribir este artículo, en Chile ronda el fantasma de la dictadura; en Bolivia, los ecos de fraude electoral resuenan en los medios de comunicación, mientras se anuncian 
Creemos que la ola de protestas que recorre a América Latina, en general, y a Colombia, en particular, se debe, principalmente, al aumento de la brecha entre los intereses de los representados y los de los representantes. Es decir, al contraste entre los asuntos que interesan a los ciudadanos y los temas de discusión de los que se ocupan y deciden, los representantes y gobernantes. Baste como ejemplo, solo para el caso colombiano, que mientras la gente se movilizaba, en medio de un sonoro "cacerolazo" en contra de las reformas económicas, pensionales y laborales, los senadores y representantes daban la espalda a la protesta y al reclamo social al dar trámite y aprobarlas. Frente a este panorama, nos preguntamos ¿qué está pasando? y ¿qué respuestas ofrecen quienes nos representan y gobiernan?

Creemos que para responder a los interrogantes el estudio, la reflexión y la discusión acerca del rol y la calidad de la representación política en los procesos democráticos se ha tornado relevante. Pero en paso previo a la reflexión y ampliación de su conocimiento, la comprensión de este fenómeno en todos los niveles a partir del estudio de uno y otra resulta fundamental. Para ello, las actitudes, las percepciones y los valores que tienen los representantes, en general, respecto de la función que cumplen y la forma como conciben sus roles resulta no solo útil sino necesaria.

En este orden, quisimos preguntarnos desde la doble perspectiva del focus y el estilo por el papel que cumplen los concejales de la ciudad de Barranquilla. Responder a este interrogante nos obliga a centrar la mirada en los políticos locales. Aquellos que pertenecen a un partido político, que se presentan a elecciones y que ganan escaños de poder en el Concejo Municipal, ${ }^{3}$ es decir, estudiar los

nuevas elecciones para elegir presidente; en Ecuador, la incertidumbre por los desaciertos del Gobierno persiste; en Colombia, se vive uno de los peores momentos de los últimos años. Un paro nacional, en clave de protesta social, que expresa una pluralidad de demandas, quejas, reclamos e indignaciones provenientes de todos los sectores: sindicales, estudiantiles, indígenas, artistas. Es una especie de catarsis social, de desahogo colectivo contra el Gobierno, las instituciones, el sistema político, el modelo económico, la corrupción y un largo etcétera, de deudas insolutas por parte de quienes representan y gobiernan al país.

3 Una de las autoridades públicas más importantes, dentro de la estructura del poder público en Colombia, es el Concejo. Aunque existía antes de la expedición de la Constitución Política de 1991, los desarrollos legales posteriores a esta han modificado su sentido y capacidades. Los concejos municipales son órganos de carácter colegiado de elección popular para periodos de cuatro años que representan el interés colectivo de los ciudadanos en el contexto municipal. Están compuestos por no menos de 7 ni más de 21 miembros, según categoría del municipio y número de habitantes, excepto el caso de Bogotá, que elige 45 concejales. Aunque los concejos municipales, institucionalmente, no hacen parte de la rama legislativa, estos órganos colegiados de representación realizan ejercicios de contrapeso al ejecutivo local. En este orden, la Constitución Política y los desarrollos legales correspondientes le asignan al concejo municipal dos grandes funciones: una de trámite normativo y otra de control político. 
políticos. Que, como bien lo señala Alcántara (2012, pp. 29), resulta relevante para la disciplina politológica, a pesar de lo incompleta que resulta la reflexión, la preocupación y la discusión disciplinar sobre este problema, principalmente en el contexto colombiano y más en el ámbito local.

El interés por abordar el estudio de quienes ejercen la representación política en los niveles subnacionales, en particular el municipal, y la relación que esta tiene con la calidad de la democracia se justifica en tanto los concejos municipales y sus actores políticos, los concejales, ${ }^{4}$ conforman un colectivo interesante, desde el punto de vista sociopolítico, de estudio e investigación por parte de la ciencia política. En este sentido, la generación de conocimiento en torno a quienes realizan la función de representación política local en el municipio colombiano se torna central para la reflexión sobre el Estado y el devenir de la democracia en las esferas local y regional.

Justifica, además, el estudio de estas élites locales en Colombia y en la ciudad de Barranquilla, principalmente: a) la importancia del Concejo como cuerpo colegiado de elección popular y, por tanto, de expresión de la vida democrática local y de sus miembros en el ejercicio del control político sobre la administración municipal o distrital, b) las ventajas políticas que ofrecen esta instancia de representación para aquellos políticos interesados en iniciar una trayectoria política de largo plazo y c) la relevancia que tiene esta corporación y sus representantes en la adopción de políticas públicas sobre planeación, finanzas públicas, medio ambiente, organización territorial, desarrollo económico y social para cada municipio o distrito.

Para el desarrollo de este trabajo, se tomó como base la estructura de la encuesta aplicada en el Proyecto Élites Latinoamericanas de la Universidad de Salamanca (PELA-USAL), instrumento previamente diseñado y validado internamente ${ }^{5}$

La primera función le permite al Concejo aprobar actos administrativos: acuerdos municipales de carácter general dentro de la jurisdicción territorial respectiva para, entre otros asuntos, la preservación y defensa del patrimonio ecológico y cultural del municipio, la elección del personero y contralor municipal, la reglamentación del uso del suelo, la aprobación del presupuesto anual de rentas y gastos, la aprobación del plan municipal de desarrollo, económico, social y de obras públicas, la autorización al alcalde para celebrar contratos, etc.

4 En adelante nos referiremos indistintamente a concejales y élite política local, entendiendo con Uriarte (1997) por élite política local a una pequeña parte de la élite local.

5 El instrumento utilizado para la recolección de los datos tiene su origen en el Proyecto Élites Parlamentarias Latinoamericanas (PELA) del Instituto de Estudios de Iberoamérica de la Universidad de Salamanca, en España. Instrumento adaptado a las necesidades y contexto local. 
y adaptado para los fines correspondientes, pero conservando tanto las preguntas centrales como los tipos de respuesta. Las bases de datos de referencia corresponden a la primera y segunda oleada de entrevistas aplicadas a los concejales del Distrito de Barranquilla, de los periodos constitucionales de 2012-2015 y 2016-2019.

En este orden, este trabajo aborda el conocimiento sobre las características sociopolíticas y demográficas básicas de los miembros que constituyen la élite política local ${ }^{6}$ de la ciudad de Barranquilla, asimismo identifica y define los factores que influyen o explican la configuración del rol de los concejales de la ciudad frente a la representación política, por lo que aproxima el estudio de las actitudes, creencias y percepciones de esta. Así, nos preguntamos ¿cómo conciben los concejales del Distrito de Barranquilla no solo los intereses que defienden sino también la forma en que se comportan en su condición de representantes políticos locales? Para responder a este interrogante, nos fijamos como propósito indagar, a partir de la percepción y actitud de la élite, por la concepción que esta tiene de la calidad de la representación política, focus y estilo. Del mismo modo, analizar la forma cómo estos conciben su papel como representantes políticos a partir de dos dimensiones: el focus (qué intereses representan) y el estilo (si se comportan siguiendo instrucciones) (cualquiera sea su fuente) o siguiendo sus propios juicios.

6 Como alternativa para zanjar la discusión sobre la conceptualización del término élite, este se equiparó al de élite parlamentaria. Para nuestro trabajo, en el plano local, los cuerpos colegiados que en mayor medida le son equiparables son los concejos distritales y municipales en Colombia, y para este caso en particular, se toma como referencia a los miembros del Concejo de la ciudad de Barranquilla para denotar a la élite política local. No estamos afirmando con esto que de forma alguna los concejos tengan la capacidad de suplantar la función legislativa, exclusiva por naturaleza y por derecho al cuerpo electo para estar en la cúspide de la rama legislativa; en el caso colombiano: el Congreso. No obstante, en cuanto a la administración de lo público en el plano local, los miembros del Concejo tienen a su cargo funciones que revisten de especial relevancia, tales como la elección de algunos funcionarios públicos, el control político al gobierno local, la aprobación o el rechazo de los actos administrativos del alcalde y de políticas públicas que impactan en particular a las ciudades y los municipios. Además, al ser elegidos por elección directa, al igual que el alcalde, comparten con este la misma base legítima que le dota de autoridad para la toma de las anteriores decisiones. De hecho, en nuestro país, la elección popular de concejales es históricamente anterior a la de alcaldes. Data del siglo XIX con la redacción de la Constitución Política de 1886, de acuerdo con la cronología del voto presentada por la Registraduría Nacional en su página web. Mientras que la elección popular de alcaldes solo se da hasta el siglo XX en 1988 y la de gobernadores en 1992, como resultado de la primera reforma constitucional de 1986 (Acto Legislativo 1) que posibilitó la descentralización política, administrativa y fiscal, y de la expedición de la Constitución Política de 1991, que derogó la centenaria de 1886, que amplió la descentralización política y posibilitó la elección popular de gobernadores. 
Para alcanzar el objetivo propuesto, el artículo se estructura en dos apartados. El primero de ellos aborda la discusión en torno a los conceptos de democracia y representación política, y los recurrentes y amplios esfuerzos por medir su calidad dando especial relevancia a aquellos que presentan un análisis de la representación política. Aproxima el estudio de las élites en la representación política. El segundo apartado presenta los resultados de la medición de las dimensiones del rol y su correlación con la calidad de la representación. Cierra el trabajo un conjunto de reflexiones en torno a las preguntas de investigación que dieron origen al artículo, en alusión también a las deficiencias del diseño institucional en el que se enmarca la figura del Concejo municipal en Colombia.

\section{Fundamentos teóricos y metodológicos}

La literatura sobre la democracia y la representación política no solo es rica y abundante sino bastante clara, por lo menos desde el punto de vista prescriptivo y de mínimos requeridos para calificar un sistema político como democrático y representativo. Hay, del mismo modo, un relativo consenso académico respecto de lo que es una y otra, como también de lo que no son estas. No obstante, en este trabajo, y en relación con la democracia representativa, un acercamiento mínimo resulta necesario, aunque no suficiente, para dar cuenta de la calidad de la representación de los concejales de la ciudad de Barranquilla desde la perspectiva del focus y del estilo.

Así, en primer lugar, abordamos la discusión alrededor del concepto de democracia, los debates que este ha suscitado y, seguramente, seguirá suscitando. En particular, nos ocuparemos de señalar los elementos mínimos considerados por el consenso académico al hablar de ella; luego, de la representación política, a partir de una breve aproximación conceptual de esta. Por último, hacer referencia al concepto de élite política para referirnos a nuestra unidad de análisis: los concejales de Barranquilla como representantes políticos en el nivel local. ${ }^{7}$

7 La Constitución Política de 1991, en su artículo 113, otorga tal calidad a los miembros de los cuerpos colegiados. A la letra dispone que "los miembros de los cuerpos colegiados de elección directa representan al pueblo y deberán actuar consultando la justicia y el bien común". 


\section{El concepto de democracia}

Cuando hablamos de democracia, ¿de qué hablamos? y ¿por qué resulta importante definir la democracia si desde la ciencia política, la sociología, la filosofía e, incluso, desde el derecho se ha estudiado y conceptuado sobre el término? Una respuesta para empezar la respuesta: porque nos ayuda a identificar qué cosa esperamos de ella; además, porque nos permite distinguir lo que debería ser con lo que es. Así, considerando con Guzmán (2008) que la democracia ha sido preocupación permanente de sociólogos, al ser la forma de sistema político adoptada y aceptada por la sociedad para la vida común, ${ }^{8}$ nos ocuparemos brevemente de aproximar e identificar los requisitos mínimos para calificar un sistema político democrático.

Las aproximaciones conceptuales al término democracia son tan extensas y variadas que es dable afirmar que la democracia es un término controvertido, multívoco, polisémico e, incluso, sistémico, que se amolda y adapta a diversos escenarios, hecho que dificulta y complejiza su tratamiento. En un claro ejemplo de estiramiento conceptual, Collier y Levitsky (2000), citados por García Díez y Mateos Díaz, (2006, p. 84), identifican, en su trabajo sobre "democracias con adjetivos", más de 550 subtipos de democracia que limitan la asignación de significado y de referente al término.

En principio, desde la acepción etimológica del término, la definición minimalista de democracia no nos resulta útil, ni mucho menos suficiente, en el momento de responder el interrogante inicial. Como no nos resulta suficiente, debemos avanzar, siguiendo a Dahl (1992, p. 131), en la búsqueda de la comprensión de lo que significa que un pueblo se autogobierne, situación que debe darse a través de algún proceso -singular- de gobierno frente al que se hace necesario hallar las características que lo hacen singular.

8 Un informe especial de la revista inglesa The Economist señala que casi la mitad de los países del mundo tienen gobiernos que pueden calificarse de democráticos, pero las "democracias plenas" son solo 28. Casi el doble de esa cifra agrega el informe, 54 países en total, constituyen a partir del puesto 29 las "democracias imperfectas", por falta de participación ciudadana y cultura política. Según los autores del informe publicado por The Economist del grupo Economist Intelligence Unit (EIU), una democracia imperfecta es en cualquier caso mejor que la ausencia total de democracia. De los 85 Estados restantes, 30 se consideran "regímenes híbridos", mientras que 55 son "autoritarios". El grupo de las 28 "democracias plenas" está dominado por los países más desarrollados, con la "notable excepción" de Italia (puesto 34), señala el informe. Son parte de ese primer grupo dos naciones latinoamericanas: Costa Rica y Uruguay, y una africana: las Islas Mauricio. Colombia se encuentra entre el grupo de democracias consideradas "imperfectas" y ocupa el puesto 67 (La Nación, 2006). 
$\mathrm{Al}$ respecto, Sartori (2002, pp. 29-69) señala que la singularidad de la democracia la encontramos si la consideramos desde a) la legitimidad que implica la existencia de elecciones libres y periódicas como mecanismo de transmisión de poder, b) la perspectiva de un sistema político distinto del demos y el kratos griego (hoy la democracia que conocemos es caracterizada por la representación) y c) lo prescriptivo, es decir, lo ideal, lo contrarreal, no obstante que la democracia se presenta como algo que se da en sentido descriptivo y no prescriptivo. Dahl (2009, p. 14), por su parte, identifica tres supuestos, relacionados entre sí, que representan criterios que permiten distinguir la democracia de la no democracia: a) la participación efectiva o la oportunidad dada a todo individuo para formular y expresar sus preferencias, b) la oportunidad de manifestar estas preferencias de manera individual o colectiva y c) la oportunidad de recibir igual trato por parte del gobierno, es decir, no ser discriminado por las motivaciones u origen de las preferencias (léase políticamente igual). A los criterios anteriores, debemos agregar, siguiendo al mismo autor las siguientes garantías institucionales: a) libertad de asociación, de expresión y de voto; b) elegibilidad para el servicio público; c) derecho de los líderes politicos para competir/luchar por los votos; d) elecciones libres e imparciales; e) diversidad de fuentes de información; f) garantías desde las instituciones que aseguren que la política del gobierno dependerá de los votos; y g) de los demás mecanismos dispuestos para la expresión de las preferencias.

En orden a lo anterior, y de forma ecléctica, entenderemos la democracia como aquel sistema político -prescriptivo y descriptivo a la vez- diferente de la democracia directa griega y de la democracia liberal, caracterizado por la existencia de un conjunto de reglas y principios que determinan cómo habrán de adoptarse las decisiones de la asociación. Tales reglas deberán ajustarse a un principio elemental: todos los miembros de la asociación son políticamente iguales.

Varios aspectos destacan de la definición anterior. En primer lugar, que es posible afirmar que de forma básica pero consensuada la democracia reúne cuatro elementos: a) elecciones libres, b) sufragio universal, c) participación y c) libertades civiles (García Díez y Mateos Díaz, 2006, p. 84). Por esta vía, la aproximación al concepto de democracia, que, en principio, puede resultar compleja, se resuelve destacando elementos básicos y centrales que no desconocen la discusión alrededor de la calidad de esta o, dicho de otra forma, de qué tanta democracia hay en un Estado. Por el contrario, permiten desenmarañar el complejo entramado de elementos que la constituyen para abordarla desde sus distintas aristas y tener 
acercamientos más concretos que den cuenta de características específicas. ${ }^{9}$ En segundo lugar, que el pueblo tiene, en esta lectura, la capacidad para definir bajo qué condiciones y sobre qué asuntos delega su autoridad y a quién.

Este aspecto es relevante para nuestro artículo en la medida en que, precisamente, plantea una observación alrededor de quiénes reciben del demos la delegación de autoridad a la que Dahl (1992) se refiere a partir de un elemento sin el cual, está claro, no se puede pensar la democracia: las elecciones. El proceso de delegación contiene, a su vez, dos aspectos clave: por una parte, el derecho a la participación pilar fundamental de la democracia, y por otra, a partir de esta, la capacidad de elegir y ser elegido para representar, lo que permite observar la democracia también desde el principio de legitimidad. Lo anterior justifica nuestra particular atención en el análisis de los políticos locales o élite política local como representantes de elección popular para ejercer tal mandato, aspecto que será ampliado en nuestro siguiente acápite.

\section{El concepto de representación política}

Una vez analizado el concepto de democracia, el paso siguiente es abordar la representación política, asunto que soporta, en buena medida, este trabajo. La consideración del componente representativo ha dado lugar a una rica literatura politológica que, con objetivos diferentes, ha intentado definir sus características, sus límites concretos y su vinculación con otros problemas. Desde Burke, en su famoso discurso de 1774, enviado a los electores de Bristol, hasta hoy, los trabajos sobre representación democrática ligados a las elecciones han sido prolijos ${ }^{10} \mathrm{y}$ ha sido abordado tanto desde la perspectiva procedimental como sustantiva.

9 Los esfuerzos por medir la calidad de la democracia son amplios. En el mundo, se han creado diferentes índices que a través de indicadores diversos dan cuenta del estado de las democracias en los países. Para mayores referencias, consúltese Polity Four, Global Democracy Ranking, Freedom House Index, Barómetro de las Américas, Democracy Index de The Economist, el Observatorio de la Democracia de la Universidad de los Andes (Colombia); y el Latinobarómetro, por ejemplo.

10 Destacan, entre otros, Fenichel (1985), Cotta (1996), Manin (1998) y Putnam (1973). 
Al respecto, Powel (2001) señala:

El primer cuerpo de investigación, sobre representación "procedimental". Comienza con los votos de los ciudadanos para los partidos en las elecciones [...] El segundo inicia con las preferencias de los ciudadanos, en lugar de con sus votos. Las elecciones de los votantes en la competencia electoral vinculan las preferencias de los ciudadanos con las preferencias y el comportamiento de los representantes legislativos. Los candidatos de los partidos toman posiciones sobre los problemas y los compromisos electorales configuran su política después de las elecciones. $L a$ elección democrática significa que las preferencias de los ciudadanos deben corresponder a las posiciones o al comportamiento de su representación (p. 1)

Nos interesa la segunda perspectiva, es decir, aquella que por su carácter sustantivo indaga la actuación de los representantes en sus actitudes y comportamientos como forma de determinar el criterio que guía su accionar y las razones que hacen que se establezca un vínculo entre los representantes y los representados. No obstante, consideramos necesario aproximar el concepto de representación política, pues, la falta de claridad en los estudios sobre representación acerca de lo que esta significa es el reflejo de lo que ocurre en la realidad (Cotta, 1996, p. 267), ya que todas las acepciones hacen referencia a las cinco variantes teóricas de Fenichel (1985). Así, para contribuir a la claridad conceptual de la representación política, consideramos que resulta necesario advertir, en primer lugar, acerca del solapamiento que se produce entre las diferentes acepciones del término y que conduce a su ambigüedad conceptual, lo que imposibilita la acumulación del conocimiento científico; $y$, en segundo lugar, que esta misma pluralidad de acepciones del término, como categoría analítica, siguiendo a González (2016, p. 18), presenta problemas de operacionalización.

Delimitamos, entonces, el concepto de representación política para hacerlo útil a los propósitos de este trabajo. Sea lo primero señalar que la principal característica de la representación política es su condición relacional -diádica- que presupone la relación entre un representante y un representado. En segundo lugar, sin restar importancia a las demás acepciones, aquí, nos ocuparemos de la representación como actuación sustantiva- perspectiva que se presenta, siguiendo a González (2016, p. 29), como una visión complementaria, que intenta suplir las posibles debilidades de las anteriores acepciones.

Así, la representación se concibe como actuación por otros, centrada en la actividad y rol de los representantes. Es, en este sentido, una actividad que se define sobre la base del interés del representado y significa, por tanto, una acción 
de protección de quien no puede o no quiere actuar en primera persona (Cotta, 1996, p. 268). Representar significa en este contexto interceder, actuar u ocuparse de los intereses de aquellas personas a las que supone se está representando. Así, la sustancia de la representación es una actividad: alguien representa aquello que guía sus acciones. Esta es la dimensión de la representación que adoptamos en este trabajo, y la definimos, siguiendo a Fenichel (1985), como

[el] actuar en interés de los representados, de una manera sensible con ellos. El representante debe actuar independientemente; su acción debe implicar discreción y discernimiento; debe ser él quien actúe. El representante debe ser también capaz de acción y de juicios independientes y no comportarse como necesitado de cuidado. [...] El representante tiene que actuar de manera que no haya conflicto [con el representado] y si este surge, se hace precisa una explicación. No debe hallarse persistentemente en disparidad con los deseos de los representados sin tener buenas razones en términos de los intereses de los representados, sin tener una buena razón de por qué sus deseos no están de acuerdo con el interés de ellos. (p. 233)

En esta concepción, actuar por otros, significa que la cosa o persona representada aparece en la acción antes que en las características del actor o en los acuerdos formales que la preceden o suceden. Lo que se espera con esta acepción de la representación es que el representante proteja los intereses de quien no puede, o no quiere, actuar en primera persona.

\section{El estudio de las élites en la representación política}

Las corrientes teóricas que amparan los estudios de las élites políticas podrían articularse en tres grandes grupos (Alcántara y Llamazares, 1997): a) estructural y relativo a la vinculación entre el origen socioeconómico de las élites y su acceso a los canales de influencia política, b) interaccionistas o estudios que relacionan las orientaciones y percepciones de las élites con los propios procesos de interacción que tienen lugar entre ellas y c) las visiones motivacionistas que parten de las vocaciones y actitudes que los representantes llevan consigo a la arena política y aquellas que desarrollan en el curso de su actividad política, de ahí que para comprender la acción política resulte indispensable pasar por el modo en que las propias élites perciben su posición y los instrumentos de que disponen para la consecución de sus fines. 
Así, el estudio de las élites políticas se ha convertido en un ámbito de atención para la ciencia política dada la centralidad que el Parlamento ha obtenido como arena en la que se instituye la representación política y donde tiene lugar el núcleo del proceso deliberativo y de elaboración de políticas públicas. No obstante, hasta mediados de la década de los noventa, el estado de la cuestión referente a América Latina presentaba una llamativa carencia en la producción de materiales y conocimiento sobre la clase política que gobernaba las recién re-instauradas democracias de la región, sobresaliendo casi exclusivamente el trabajo de Highley et al. (1992). Las razones por las cuales se produce esta carencia pueden, principalmente, articularse en torno a lo académico en tanto se presenta no solo dificultad de acceso a los recursos materiales y humanos de los que se nutren los estudios empíricos de estas características, sino por el desarrollo del propio interés académico, centrado en los procesos de transición democrática o en los arreglos institucionales en que se articulaban los regímenes políticos resultantes.

El cuerpo teórico que envuelve esta propuesta de estudio de la élite política local articula los niveles macro y micro del análisis, esto es, el contexto nacional y los subsistemas políticos en los cuales se insertan. La articulación de ambos planos se hace en una doble dirección: por un lado, el impacto que los cambios institucionales (macro), los aspectos contextuales y la experiencia histórica de la región y de cada municipio tiene sobre las trayectorias políticas, los posicionamientos ideológicos, los valores y las creencias de los representantes políticos y, por otro, el efecto que este perfil actitudinal, ideológico y de opinión ejerce sobre el proceso de elaboración de políticas públicas, la representación y la dinámica del sistema.

Justificamos, como lo hacen, respecto del estudio de la élite en distintos niveles, Alcántara (2006), Marenghi y García (2006), y Solís (2015), que el estudio de esta particular clase política resulta relevante para la ciencia política y para el sistema político mismo, por cuanto esta es al mismo tiempo que representante actor capaz de influir y orientar las actitudes políticas de los ciudadanos e impactar la cultura política en una sociedad dada. Bien, respecto de la élite, lo señala Solís (2015):

La élite política [...] es entendida como un actor relevante en el juego democrático y en el análisis-comprensión de todo sistema político. En la élite política, sostenemos, se materializa cualquiera de las direcciones en las que se ha desarrollado la teoría de la representación, esto es, que puede ser entendida como delegada del poder, que ha recibido un mandato del pueblo; que es representativa de, en la medida en que debería asemejarse al grupo que representa y que es responsable, que debe rendir cuentas de su actuación, cuando menos, a las bases sociales que le eligieron. (p. 7) 
Reiteramos, como en otros pasajes de este trabajo, la necesidad de dar inicio, a través de aproximaciones similares, al estudio de las élites locales en la región y en el país.

\section{Los concejales en la ciudad de Barranquilla: ¿quiénes son?, ¿qué intereses defienden?, ¿a quién escuchan?}

Si bien el propósito de este trabajo no es señalar cómo son en cuanto a su edad o formación los concejales del Distrito de Barranquilla, consideramos necesario hacer una aproximación a esa caracterización, si se quiere, básica de ellos. Así, brevemente señalaremos algunas de las características más sobresalientes de los miembros de este cuerpo colegiado. Para ello, podríamos tomar como punto de partida las preguntas ¿quiénes son los concejales de la ciudad de Barranquilla? y ¿cómo perciben determinados asuntos?

En cuanto a su perfil, la élite política local para el periodo antes indicado está conformada por 21 concejales, con una edad mínima registrada de 37 años. La mayoría de los concejales para el periodo (cerca del $70 \%$ ) no supera los 54 años, lo que es coherente con la edad media, fijada en 52 años. Uno de los datos más llamativos es que en la conformación del Concejo solo hay para el periodo en análisis una mujer, no obstante, existir una ley de cuotas.

La mayoría de los concejales posee estudios superiores en los niveles universitario o de grado superior $(52,4 \%)$ y un $38,1 \%$ estudios de posgrado, porcentaje que puede considerarse, por lo menos formalmente, como una fortaleza del Concejo distrital. Más cuando, como lo señala Ánzola (2011), citado por Solís (2015), que para 2011 solo un 3,1\% de los colombianos contaban con formación a este nivel. Aún más, podríamos señalar, sin verificar lo afirmado, que ese nivel de estudios de los concejales de la ciudad de Barranquilla contrasta sustancialmente con el de otras corporaciones de igual naturaleza en la Costa Caribe y del resto del país, excepto los casos de las ciudades de Medellín, Cali y Bogotá.

Ideológicamente, la élite política local no solo reconoce la escala izquierdaderecha, sino que se ubica y autoubica a su partido. La mayoría de ellos se ubica a sí mismo y a sus partidos, estos últimos considerados mayoritariamente un 
$90 \%$ como partidos de centroderecha y derecha. Solo un concejal se declara de centroizquierda. Estas posturas en la escala coinciden con la manifestada frente a problemas como el divorcio o el aborto. Para el $57 \%$ de los entrevistados, se debe penalizar el aborto, y el $67 \%$ de estos se muestra partidario de la prohibición del divorcio.

Respecto de su aprendizaje político, afirmamos que, por lo menos, cinco de cada diez concejales en sus procesos de aprendizaje político observan procesos de socialización temprana. El $57 \%$ de ellos reconoce que en su hogar se hablaba mucho o bastante de política durante su infancia y juventud, lo que pudo haber impactado su vocación por el activismo político, hecho que no puede pasar inadvertido en este trabajo. Por el contrario, la vinculación o el acceso a la actividad política en la Costa Caribe, principal aunque no exclusivamente, se hace por influencia familiar.

Ahora, en cuanto a los valores democráticos, el $77 \%$ de los concejales consideran que la democracia es preferible a cualquier otro sistema de gobierno; asimismo, el $67 \%$ de estos consideran que la democracia colombiana, y por extensión la local, es estable. Comparativamente, la percepción que tiene la élite nacional respecto de la preferencia por la democracia la élite local ubica su preferencia 27 puntos porcentuales por debajo de la nacional. Este dato tampoco puede pasarse por alto, y bien valdría la pena indagar más la democracia en el ámbito local. Llama la atención que la valoración de la democracia por parte de la élite política local de la ciudad de Barranquilla es superior a la media expresada por los ciudadanos de América Latina tomando como base los resultados de la última encuesta LAPOP $^{11} 2016$, en que el 57,8 \% de los encuestados manifestó estar de acuerdo con que, pese a los problemas que puede tener la democracia, esta es preferible a cualquier otra forma de gobierno.

11 La encuesta LAPOP es resultado del Proyecto de Opinión Pública de América Latina, liderado por la Universidad de Vanderbilt. Cada dos años realiza la encuesta del Barómetro de las Américas, en la que se entrevistan ciudadanos de 26 países, que incluyen a Norteamérica, Centroamérica y Suramérica, además del Caribe. Para ver el análisis de los resultados 20162017 véase Cohen et al. (2016). 


\section{El focus y el estilo de la representación política en la ciudad de Barranquilla: ¿qué intereses defienden?, ¿a quién escuchan?}

Antes del análisis que nos permitía observar la posición que los concejales de la ciudad de Barranquilla asumen en torno a los intereses (generales o particulares) por los que se preocupan en su rol de representantes más cercanos a los ciudadanos y a la forma como estos se comportan (siguiendo instrucciones o asumiendo juicios propios), para corroborar que estas medidas tengan sentido para la élite política local (concejales) de la ciudad, resulta necesario señalar que llevamos a cabo un análisis de correlación de Pearson entre las variables cuantitativas focus y estilo, tras el cual se comprobó que no guardan relación estadísticamente significativa. ${ }^{12}$ Por tanto, resulta válida la separación de las dos dimensiones de la representación local, pues captan aspectos distintos e independientes del rol representativo a este nivel. No obstante, al relacionar los indicadores utilizados en cada dimensión, contrario a lo que encontraron Marenghi y García (2005, pp. 38-39), solo dos de estos, en cada dimensión, mostraron correlaciones estadísticamente significativas.

Ahora, respecto del focus y estilo de los concejales de Barranquilla, los resultados nos permiten observar cómo se muestran los concejales por partido político e individualmente. Respecto del índice de focus, los concejales se muestran en una posición que se inclina levemente hacia la defensa de intereses generales $(3,52$ en la escala de 0 a 6 ). Con respecto al estilo, la media es de 3,05, lo que permite afirmar que los concejales tienen un estilo aún por definir.

Ahora, si bien se observa una posición media, tanto para el focus como para el estilo, los resultados nos muestran que las posiciones varían en un rango que va desde 0,75 hasta 4,25 para el focus, y de 0,78 hasta 4,99 para el estilo. Esto nos permite corroborar la indefinición de la élite local barranquillera en cuanto al focus y estilo de su rol como representantes.

Por otro lado, respecto de a quiénes representan los concejales, preguntamos: “'A quién cree Ud. que representa en su actividad como concejal?", los datos nos

12 El índice de correlación de Pearson entre las variables focus y estilo es de -0,234 y su significación es de 0,306. 
muestran que, mayoritariamente, los representantes locales manifiestan representar al conjunto de los electores del distrito, el $86 \%$ (30 concejales) de ellos así lo consideran, mientras solo un $8 \%$ (3 concejales) y un $6 \%$ ( 2 concejales) de estos afirman representar a su partido y a los electores de su partido, respectivamente (tabla 1).

Tabla 1. A quiénes representan los concejales (por partido político)

\begin{tabular}{lccccccccc}
\hline & Liberal & Conservador & $\begin{array}{c}\text { Polo } \\
\text { Democrático }\end{array}$ & $\begin{array}{c}\text { de } \\
\text { la U }\end{array}$ & $\begin{array}{c}\text { Cambio } \\
\text { Radical }\end{array}$ & AICO & Mio & $\begin{array}{c}\text { Voluntad } \\
\text { Popular }\end{array}$ & 9 \\
$\begin{array}{l}\text { Votantes del } \\
\text { partido }\end{array}$ & 0 & 1 & 0 & 0 & 0 & 0 & 0 & 1 & 0 \\
\hline $\begin{array}{l}\text { Electores del } \\
\text { municipio }\end{array}$ & 7 & 8 & 0 & 3 & 6 & 1 & 2 & 2 & 1 \\
\hline $\begin{array}{l}\text { Partido } \\
\text { político }\end{array}$ & 0 & 2 & 1 & 0 & 0 & 0 & 0 & 0 & 0 \\
\hline
\end{tabular}

AICO: Autoridades Indígenas de Colombia; MIO:

Movimiento de Inclusión y Oportunidades.

Fuente: Elaboración propia a partir de datos de la encuesta.

Por otra parte, pensando en la medida en que los concejales consideran la opinión de distintos actores de la política local en el momento de tomar decisiones en su actividad como concejales, les preguntamos ¿Hasta qué punto (mucho, bastante, poco o nada) tiene Ud. en cuenta la opinión de cada uno de los siguientes grupos, personas o instituciones cuando toma decisiones?: los líderes de su partido tanto nacionales como regionales y otros concejales de su partido (cúpulas de los partidos), los afiliados a su partido y los votantes de su partido (bases de los partidos). La tabla 2 nos muestra los resultados, en promedio, ofrecidos por la élite local.

Tabla 2. Influencia de diferentes actores en las decisiones políticas de los concejales (en promedio)

\begin{tabular}{cc}
\hline \multicolumn{1}{c}{+} & - \\
\hline Electores de su circunscripción: 3429 & Medios de comunicación: 2886 \\
\hline La opinión pública en general: 3486 & Otros concejales del partido: 2629 \\
\hline Votantes de su partido: 3229 & El Gobierno: 2886 \\
\hline
\end{tabular}

Fuente: Elaboración propia a partir de datos de la encuesta. 
En cuanto a cómo evalúan ellos la calidad de la representación local, el análisis de los datos nos permite señalar que esta tiene una alta valoración en tanto los concejales fijan su calidad, en promedio, en 3,82 en una escala de 1 a 5 en que 1 es baja y 5 alta.

Calificada la calidad de la representación, quisimos indagar los elementos que se consideran importantes para hacer referencia a una representación de calidad. Preguntamos, entonces, a los concejales: "¿Qué elementos, en primer, segundo y tercer lugar, considera importantes para la calidad de la representación?”.

La tabla 3 nos indica que 23 concejales (66\%) consideran que el principal elemento relacionado con la calidad de la representación es la legitimidad ciudadana, en un segundo plano el alto nivel de formación y en un tercer lugar la correspondencia de los intereses del concejal con respecto al de los electores y que el concejal rinda cuentas de su actuación pública en el Concejo. Asimismo, 9 concejales (26\%) estiman que el principal elemento relacionado con la calidad de la representación es que el concejal rinda cuentas de su actuación pública en el Concejo y en segundo lugar que haya acatamiento y respeto por la ley por parte de los concejales en el ejercicio de sus funciones. Por último, 2 concejales $(8 \%)$ señalan que el principal elemento relacionado con la calidad de la representación es el alto nivel de formación de los concejales y en un segundo plano la legitimidad ciudadana.

Tabla 3. Calidad de la representación local (por partido político y elementos)

\begin{tabular}{|c|c|c|c|}
\hline \multirow{2}{*}{ Principal elemento } & \multicolumn{3}{|c|}{ Calidad de la representación (1-5) } \\
\hline & Alta (4-5) & Media (3) & Baja (1-2) \\
\hline 1. Legitimidad ciudadana & $\begin{array}{l}\text { U (2); Conservador (4); } \\
\text { Voluntad Popular (2) }\end{array}$ & $\begin{array}{c}\text { Cambio } \\
\text { Radical (1) }\end{array}$ & Liberal (1) \\
\hline $\begin{array}{l}\text { 2. Alto nivel de formación } \\
\text { de los concejales }\end{array}$ & $\begin{array}{l}\text { Conservador (1); Cambio } \\
\text { Radical (2); AICO (1); } 9 \text { (1) }\end{array}$ & Liberal (1) & $\begin{array}{l}\text { Cambio Radical (1); } \\
\text { Conservador (1) }\end{array}$ \\
\hline $\begin{array}{l}\text { 3. Trayectoria y experiencia } \\
\text { política de los concejales }\end{array}$ & Liberal (1); Conservador (1) & $\mathrm{MIO}(1)$ & \\
\hline $\begin{array}{l}\text { 4. Correspondencia de los } \\
\text { intereses del concejal con } \\
\text { respecto al de los electores }\end{array}$ & $\begin{array}{l}\text { Cambio Radical (1); } \\
\text { Voluntad Popular (1); } \\
\text { Conservador (1) }\end{array}$ & $\begin{array}{l}\text { Cambio } \\
\text { Radical (1) }\end{array}$ & \\
\hline $\begin{array}{l}\text { 5. Concejal rinda cuentas } \\
\text { de su actuación pública en } \\
\text { el concejo }\end{array}$ & Liberal (2); Conservador (1) & $\begin{array}{c}\text { Polo } \\
\text { Democrático } \\
\text { (1); MIO (1); } \\
\text { Liberal (1) }\end{array}$ & \\
\hline
\end{tabular}


6. Posibilidad que el ciudadano revise y evalué la actividad de los concejales

7. Acatamiento y respeto por la ley por parte de los concejales en el ejercicio de sus funciones
Conservador (1)

Conservador (1)

Liberal (1);

$\mathrm{U}(1)$

Fuente: Elaboración propia a partir de datos de la encuesta.

Hasta aquí hemos aproximado la descripción de la élite local. Pasemos ahora a la explicación de su rol y su estilo, determinantes de la representación.

\section{Una explicación del rol de la representación local en la ciudad de Barranquilla}

Llegados a este punto, debemos señalar que tan solo hemos mostrado la posición que los partidos políticos y los concejales de la ciudad de Barranquilla observan frente al rol de la representación. Es necesario ahora, dado que los fenómenos políticos responden a la interacción de múltiples variables, que a menudo son difíciles de aprehender por su carácter cambiante y poco sujetos a la cuantificación (Marenghi y García Montero, 2006, p. 56), detallar los factores explicativos del focus y el estilo (la tabla 1 muestra cuatro grupos de factores explicativos para el estilo y tres para el focus). Para el estilo, son estos: a) percepciones sobre la importancia, el funcionamiento y la organización de los partidos políticos, b) ideología política partidista, c) carreras políticas y d) características sistémicas. Para la dimensión del focus, las variables predictoras están agrupadas en tres categorías: a) organización partidista, b) sistema político y c) coyuntura política.

Lo que sigue ahora es dar respuesta a una serie de interrogantes relacionados con el rol de la representación de la élite política local de la ciudad de Barranquilla, tales como ¿cuáles son los factores de influencia que hacen a los concejales ser partidarios de seguir sus propios juicios o les inclina a seguir instrucciones?, ¿qué variables influyen para que se manifiesten a favor de la defensa de intereses particulares o generales?, ¿condicionan estos factores el estilo y el focus de la representación? 
Como se muestra en la tabla 4, la dimensión de estilo guarda relación con catorce variables independientes que unidas explican un 69 \% de la inclinación a seguir juicios propios o a seguir instrucciones. El sentido explicativo de algunas variables va encaminado en direcciones diferentes de la teoría que formaba las hipótesis iniciales y que podría estar indicando la ausencia de un estilo definido. De estas catorce variables, no todas tienen el mismo peso sobre este; la que muestra mayor poder de predicción es la de Pertenencia del escaño al partido. Esta relación es contraria a la hipótesis que indica que los concejales que opinan que el escaño pertenece al partido político y que, por tanto, cuando un concejal lo abandona debe renunciar a su cargo mantiene un estilo más favorable a seguir instrucciones, ya que en este caso son más permeables a tener juicios propios.

La segunda de las variables en fuerza predictora es la de Baja democracia interna que indica que aquellos concejales que perciben que el grado de democracia interna de su partido es bajo tienen una inclinación superior a seguir sus propios juicios. La tercera variable es la que muestra el Nivel bajo de militancia propio en los partidos, lo que confirma la hipótesis de que cuando hay bajo nivel de militancia los concejales tienden a seguir juicios propios. La cuarta variable es la Necesidad de los partidos para la democracia, contraria a la hipótesis: los concejales que consideren que los partidos son necesarios para la democracia tienden a seguir juicios propios. La quinta variable es el Nivel medio de militancia propio de los partidos, que tiende a darse cuando los concejales siguen juicios propios. La sexta es el Nivel medio de militancia de partido, que tiende a estar asociado con concejales que siguen juicios propios. La séptima variable es Democracia interna media que coincide con concejales que tienden a seguir juicios propios, y la octava variable sobre la Ubicación ideológica propia de centro. Sin embargo, la novena variable, Ubicación ideológica del partido, indica, contrario a la hipótesis, que los partidos de derecha tienden a tener concejales que sigan juicios propios.

Conforme a la décima variable, el Nivel bajo de militancia propio, se puede confirmar la hipótesis de que, cuando los niveles de militancia allí son bajos, los concejales tienden a tener mayor juicio propio. La undécima variable, Ubicación ideológica propia de izquierda, confirma que los concejales que tienden a tener posiciones de izquierda propenden a seguir su propio juicio. La duodécima variable, Participación popular en el propio partido, conforme a la hipótesis, muestra que la percepción de que la participación popular en el partido es alta está asociada con concejales permeables a seguir instrucciones. La penúltima variable, Relación partidos y sociedad, muestra que los concejales que perciben que los partidos están alejados de la sociedad tienden a apoyarse en las instrucciones del partido, contrario a la hipótesis. Y, la última variable, Estabilidad de la democracia, confirma 
la hipótesis de que los concejales que poseen una opinión negativa acerca de la estabilidad de la democracia del país mantienen un estilo caracterizado por el seguimiento de sus propios juicios.

Tabla 4. Explicación del rol representativo (33 obvs estilo y 32 obvs focus)

\begin{tabular}{|c|c|c|c|}
\hline Dimensiones & Predictores & Coeficiente & $\begin{array}{l}\text { Coeficiente } \\
\text { Estand. }\end{array}$ \\
\hline $\begin{array}{l}\text { Estilo de la } \\
\text { representación }\end{array}$ & Constante & $1,648^{* * *}$ & \\
\hline \multirow{14}{*}{$\begin{array}{l}\text { R2 0,829 } \\
\text { Adjusted R2 0,697 } \\
\text { Residual Std. Error } \\
0,551(\mathrm{df}=18) \\
\text { F Statistic 6,251*** } \\
\text { (df }=14 ; 18) \\
\text { Note: }{ }^{*} p<0,1 ; \\
{ }^{* \star} p<0,05 ;{ }^{* \star \star} p<0,01\end{array}$} & $\begin{array}{c}\text { Participación popular en el propio } \\
\text { partido }\end{array}$ & $-0,571$ & $-0,224$ \\
\hline & Nivel medio de militancia de partido & $0,917^{*}$ & $0,341^{*}$ \\
\hline & Nivel bajo de militancia de partido & $1,082^{*}$ & $0,392^{*}$ \\
\hline & Democracia interna media & $-0,701^{*}$ & $-0,254^{*}$ \\
\hline & Baja democracia interna & $-1,147^{\star \star *}$ & $-0,427 * * *$ \\
\hline & Relación partidos y sociedad & 0,555 & 0,211 \\
\hline & Nivel medio de militancia propio & $-0,865^{*}$ & $-0,313^{*}$ \\
\hline & Nivel bajo de militancia propio & $-0,640$ & $-0,244$ \\
\hline & Pertenencia del escaño al partido & $1,233^{\star * *}$ & $0,447^{* * *}$ \\
\hline & $\begin{array}{l}\text { Necesidad de los partidos para la } \\
\text { democracia }\end{array}$ & $0,909 * * *$ & $0,363^{* * *}$ \\
\hline & Estabilidad de la democracia & 0,519 & 0.201 \\
\hline & Ubicación ideológica del partido & $0,832^{* *}$ & $0,251^{* *}$ \\
\hline & $\begin{array}{l}\text { Ubicación ideológica propia de } \\
\text { izquierda }\end{array}$ & $0,814^{*}$ & $0,229 *$ \\
\hline & $\begin{array}{l}\text { Ubicación ideológica propia de } \\
\text { centro }\end{array}$ & $1,895^{\star *}$ & $0,253^{* *}$ \\
\hline $\begin{array}{l}\text { Focus de la } \\
\text { representación }\end{array}$ & Constante & $2,624^{* * *}$ & \\
\hline $\begin{array}{l}\text { R2 0,164 } \\
\text { Adjusted R2 0,107 } \\
\text { Residual Std. Error } \\
1,159(\mathrm{df}=29)\end{array}$ & $\begin{array}{l}\text { Papel de los líderes nacionales en el } \\
\text { nombramiento de los candidatos }\end{array}$ & $1,342^{* *}$ & $0,388^{* *}$ \\
\hline $\begin{array}{l}\text { F Statistic } 2,854^{*} \\
(\mathrm{df}=2,29) \\
\text { Note: }{ }^{\star} \mathrm{p}<0,1 ; \\
{ }^{* \star} \mathrm{p}<0,05 ;{ }^{* \star *} \mathrm{p}<0,01\end{array}$ & $\begin{array}{l}\text { Nivel de autonomía de los políticos } \\
\text { regionales }\end{array}$ & $0,905^{*}$ & $0,374^{*}$ \\
\hline
\end{tabular}

Fuente: Elaboración propia de datos recolectados mediante encuesta aplicada a los 33 concejales de la ciudad de Barranquilla. 
En cuanto a los resultados del focus, hay dos variables con relevancia estadística relacionadas con el nombramiento de candidatos y la influencia de los líderes nacionales y regionales. Sin embargo, la predicción en la varianza de la dimensión focus es solo del $10 \%$; aunque es coherente con la teoría en la primera variable, en la segunda no es así. La primera es la del papel de los líderes nacionales en el nombramiento de los candidatos que confirma la hipótesis de que en los partidos en los que los líderes nacionales son los que deciden el nombramiento de los postulantes a elecciones sus concejales se mostrarán más favorables a defender interese generales. La segunda es el nivel de autonomía de los políticos regionales que muestra que aquellos partidos en los que existe un alto nivel de autonomía para la actuación de políticos regionales los concejales muestran una inclinación superior a la defensa de intereses generales.

\section{Conclusiones}

Sea lo primero señalar que el trabajo que presentamos es deudor de un proyecto de investigación de mayor alcance. ${ }^{13}$ Es, si se quiere, un paso más en la pretensión de observar, conocer, saber y predecir acerca de un fenómeno que todos dicen conocer pero que en realidad se desconoce: ¿quiénes son?, ¿qué actitudes y percepciones tienen?, ¿a quién representan? En ese sentido, la primera aseveración en clave de conclusión de este trabajo es que es una aproximación, un esfuerzo investigativo en construcción, inacabado, y no por ello carente de la rigurosidad académica y metodológica propia de la disciplina.

En segundo lugar, resulta claro que los indicadores que hemos utilizado para valorar el rol de la élite política local de la ciudad de Barranquilla, a partir de focus y el estilo de los concejales de la ciudad, es sujeto y objeto de debate académico; más tratándose de un estudio de caso. Sin embargo, la justificación del por qué lo hemos hecho esperamos sea considerada o, por lo menos, aceptada a estos efectos como válida.

Antes de señalar las principales conclusiones resulta necesario para una mejor comprensión de lo que sigue hacer una breve anotación respecto de los partidos

13 Este trabajo se enmarca en el Proyecto Élites políticas locales del Caribe colombiano, liderado por Carlos Guzmán Mendoza. Proyecto que tiene como uno de sus propósitos construir una base de datos que abarque en el tiempo una robusta y significativa base de datos sobre los concejales de los municipios de los ocho departamentos del Caribe. 
políticos, seno de los concejales, en Colombia. En este orden, se señala que los partidos políticos son instituciones fundamentales de la democracia sin adjetivos; son instituciones que intermedian entre la sociedad civil y el Estado; se encuentran en el centro del proceso electoral, no obstante, la acentuada conexión personalista entre votantes y candidatos, propia de las democracias en desarrollo (Mainwaring y Torcal, 2005, p. 147); y son actores protagónicos de la gestión del poder político, la Administración pública y la definición de políticas. Por su parte, además de las razones anteriores, el sistema partidario es el resultado no solo de la interacción entre las unidades partidistas, sino de la relación e interacción que estos, en conjunto, tienen con las estructuras gubernamentales y los diferentes aparatos burocráticos (Guzmán, 2005, p. 55).

¿Qué partidos políticos han participado en los procesos electorales de los años 2008-2011, 2012-2015 y 2016-2019 en la ciudad de Barranquilla? ¿Cuál es su origen? Señalemos, en primer lugar, que la característica principal respecto de los partidos políticos que compitieron y compiten por el poder político en la ciudad son el resultado de la reforma política de $1986,{ }^{14}$ que agudizó el faccionalismo regional, producto de la desideologización y la crisis del bipartidismo tradicional, y puso al descubierto la fuerte atomización partidista en Colombia, para dar paso a una ascendente clase política regional. Y, en segundo lugar, que la conexión entre los electores y los partidos políticos se basa, principalmente, en vínculos personalistas y clientelares, y no en afinidades ideológicas o programáticas con los partidos.

Con este antecedente, la primera conclusión que se deriva es que el rol de los representantes locales, a partir del focus y el estilo, podría estar asociado con el origen faccional de los partidos políticos que compiten por el poder en la ciudad. Situación que agudizó el fuerte personalismo de la política colombiana, el fortalecimiento de los caciquismos locales y regionales, que hace que los partidos en el ámbito local sean, más que partidos, franquicias electorales que representan poco menos que intereses generales o de partido. Por el contrario, y léase como especulación, representan los intereses particulares de casas y grupos económicos fuertes,

14 La descentralización en Colombia fue el resultado de la influencia de la tercera ola democratizadora que recorrió América Latina. En el país, se expresó a través de la devolución de facultades políticas, administrativas y fiscales a las entidades territoriales. Se materializó mediante el Acto legislativo 1/1986, de 9 de enero, que posibilitó la primera elección popular de alcaldes. Elección que se extendió, luego, a los gobernadores en razón de la entrada en vigencia de la Constitución Política de 1991. 
que, enmascarados en la política, incrementan y mantienen su poder hegemónico de pretensiones económicas.

La segunda conclusión, en relación con el focus y el estilo de los concejales, es la indefinición que estos muestran en el momento de decir si representan intereses generales o particulares (focus); similar situación, de indefinición del estilo, se observa en los concejales, quienes dan la misma importancia, desde el punto de vista de la influencia, a las bases, las cúpulas e, incluso, al gobierno local. El sentido explicativo de algunas variables que va encaminado en direcciones diferentes de la teoría que formaba las hipótesis iniciales podría estar indicando la ausencia de un estilo definido. ¿Tal indefinición podría calificarse de dilema? ¿'Dilema de la representación? ¿O, según Walzer (2010, p. 386), "problema de las manos sucias"?

En cuanto a las explicaciones, tercera conclusión, del rol representativo de los concejales de la ciudad de Barranquilla, los análisis de los resultados nos muestran que, respecto del estilo, no obstante, el sentido explicativo de algunas variables que se orienta en direcciones diferentes de la teoría que formaba las hipótesis iniciales, las variables utilizadas poseen valor explicativo suficiente para confirmar las hipótesis formuladas. Es decir, que los concejales que opinan que el escaño pertenece al partido político y que, por tanto, cuando un concejal lo abandona debe renunciar a su cargo mantienen un estilo más favorable a seguir instrucciones, ya que en este caso son más permeables a tener juicios propios.

Respecto de las del focus, cuarta conclusión, hay dos variables con relevancia estadística relacionadas con el nombramiento de candidatos y la influencia de los líderes nacionales y regionales. Sin embargo, la predicción en la varianza de la dimensión focus es solo del $10 \%$; aunque coincide con la teoría en la primera variable, en la segunda no es así. La primera es la del papel de los líderes nacionales en el nombramiento de los candidatos que confirma la hipótesis de que en los partidos en los que los líderes nacionales son los que deciden el nombramiento de los postulantes a elecciones sus concejales se mostrarán más favorables a defender intereses generales. La segunda es el nivel de autonomía de los políticos regionales que muestra que aquellos partidos en los que existe un alto nivel de autonomía para la actuación de políticos regionales los concejales muestran una inclinación superior a la defensa de intereses generales.

Una quinta conclusión, vinculada a los partidos políticos, nos indica que el nivel de democracia interna que observan los partidos y que perciben los concejales tiene una significativa fuerza predictora en relación con el rol de los representantes locales. Esto indica que aquellos concejales que perciben que el grado de 
democracia interna de su partido es bajo tienen una inclinación superior a seguir sus propios juicios. Esta conclusión estaría, según los resultados del modelo, asociada al factor militancia partidista. Un bajo nivel de militancia en los partidos políticos que participan de la lucha por la representación en el Concejo distrital confirma la hipótesis de que, cuando hay bajo nivel de militancia, los concejales tienden a seguir juicios propios.

Finalmente, reiteramos el carácter ambicioso y de largo plazo del proyecto de élites políticas locales, que encuentra y hace de nuestra investigación un punto de partida para un mejor conocimiento y comprensión de nuestros dirigentes, de aquellos que, elegidos por nosotros, tienen cargos de poder y cuyo rol determina de forma trascendental el funcionamiento de la democracia, que es, finalmente, nuestro principal objeto de análisis y lo que nos motiva a no desistir en la búsqueda de respuestas sobre el cómo hacerla más efectiva, estable y capaz de dar respuesta a las necesidades de las sociedades en que se instaura.

\section{Referencias}

Acto legislativo 1/1986, de 9 de enero, por el cual se reforma la Constitución Política. Diario Oficial, núm. 37304 (1986).

Alcántara Sáez, M. (Ed.) (2006). Políticos y política en América Latina. Siglo XXI.

Alcántara Sáez, M. (2012). El oficio del político. Tecnos.

Alcántara Sáez, M. y Llamazares Valduvieco, I. (1997). El análisis de los diputados latinoamericanos en el contexto de los estudios sobre la clase política: características, objetivos y estrategias de investigación. América Latina Hoy, 16, 15-28. https://gredos.usal.es/handle/10366/72361

Cohen, M. J., Lupu, N. \& Zechmeister, E. J. (2016). The political culture of democracy in the Americas, 2016/17. United States Agency for International Development.

Colomer, J. M. (2001) Instituciones políticas. Ariel.

Cotta, M. (1996). Parlamentos y representación. En G. Pasquino, S. Bartolini, M. Cotta, L. Morlino y A. Panebianco, Manual de ciencia política. (pp. 265-310). Alianza.

Dahl, R. A. (1992). La democracia y sus críticos. Paidós.

Dahl, R. A. (2009). La poliarquía, participación y oposición. Tecnos.

Fenichel Pitkin, H. (1985). El concepto de representación. Centro de Estudios Constitucionales.

García Díez, F. y Mateos Díaz, A. (2006). El proyecto élites parlamentarias latinoamericanas: continuidades y cambios, 1994-2005. En M. Alcántara Sáez (Ed.), Políticos y política en América Latina. (pp. 3-28). Siglo XXI.

González Tule, L. A. (2016). El rol de representación de los diputados federales en Brasil y México: mirada a la experiencia latinoamericana. Universidad del Norte.

Guzmán Mendoza, C. E. (2005). Política, descentralización y subsistemas regionales de 
partidos en Colombia, 1988-2000: una explicación teórica y un análisis empírico. Universidad de Ibagué.

Guzmán Mendoza, C. E. (2008). La política como objeto de reflexión. Revista de Derecho, 30, 268-298. http://www.scielo.org.co/scielo.php?pid=S0121$86972008000200010 \&$ script $=$ sci_arttext $\&$ tlng $=$ en

Higley, J., Gunther, R. \& John, H. (Eds.). (1992). Elites and democratic consolidation in Latin America and Southern Europe. Cambridge University Press.

La Nación. (2006, noviembre 22). Según un ranking publicado por The Economist. Solo 28 países tienen una "democracia plena". https://www.lanacion.com.ar/el-mundo/ solo-28-paises-tienen-una-democracia-plena-nid861039/

Mainwaring, S. y Torcal, M. (2005). La institucionalización de los sistemas de partidos y la teoría del sistema partidista después de la tercera ola democratizadora. América Latina Hoy, 41, 141-173. https://www.redalyc.org/pdf/308/30804107.pdf

Manin, B. (1998). Los principios del gobierno representativo. Alianza.

Marenghi, P. y García Montero, M. (2006). El rompecabezas de la representación: qué intereses defienden y cómo se comportan los legisladores latinoamericanos. En M. Alcántara Sáez (Ed.), Políticos y política en américa Latina. (pp. 29-81). Siglo XXI. https://dialnet.unirioja.es/servlet/articulo?codigo $=5034881$

Powell, B. (2001). Democratic Representation: Two Contributions from Comparative Politics. Trabajo presentado en Annual Meeting of the Political Science Association, Chicago, EE. UU.

Putnam, R. (1973). The beliefs of politicians: Ideology, conflict, and democracy in Britain and Italy. Yale University Press.

Sartori, G. (2002). Representación. En Autor, Elementos de teoría política. (pp. 257-277). Alianza.

Solís Menco K. I. (2015). Élites políticas en el Caribe colombiano: significados de democracia y confianza institucional, el caso de Barranquilla. Tesis de maestría en ciencia política. S/P. Universidad del Norte.

Subirats, J. (2012). Lejanía. En J. M. Vallès y X. B. Hernández, Política para apolíticos: contra la dimisión de los ciudadanos. (pp. 29-32). Ariel.

Uriarte, E. (1997). El análisis de las élites políticas en las democracias. Revista de Estudios Políticos, 97, 249-275. https://recyt.fecyt.es/index.php/RevEsPol/article/download/45470/26990

Walzer, M. (2010). Pensar políticamente. Paidós. 